\title{
小照射野領域における照射野係数のフィルム法による検討
}

\author{
池 田郁 夫・池 崎廣海・松 本 直 素 \\ 小松一之・岩 本 俊 彦・小柳 正 道 \\ 杏林大学医学部付属病院放射線科 \\ （論文受理１994年11月14日） \\ （最終論文受理１995年 9 月22日） \\ (Code No. 430, 800, 850)
}

Key words: Field factor, Small field, Film dosimetry, Monitor unit

\section{FIELD FACTORS FOR SMALL FIELDS MEASURED BY FILM DOSIMETRY (THE MOST COMMON WAY.)}

\author{
Ikuo Ikeda, Hiromi Ikezaki, Naomoto Matsumoto \\ Kazuyuki Komatsu, Toshiniko Iwamoto and Masamichi Koyanagi \\ Department of Radiological Technology, Kyorin University Hospital
}

\section{Summary}

Field factor $\left(\mathrm{F}_{\mathrm{A}}\right)$ for a small field is able to be obtained by film dosimetry with conception of monitor unit (MU) which provides constant density.

Close agreement between $F_{A}$ measured by film dosimetry and $F_{A}$ measured by the ionization chamber and the semiconductor detector, could be obtained.

In this method, $\mathrm{F}_{\mathrm{A}}$ is able to be measured without converting film density into an irradiated dose.

This method could also be applied to the measurement of $F_{A}$ for infinitesimally small irradiated fields.

\section{1.はじめに}

Stereotactic radiosurgery ${ }^{60} \mathrm{Co} \gamma$ 線を使用する Gamma unit と高エネルギーX線を使用する直線加速器 による方法が行われている.

直線加速器による radiosurgeryには直径 $3 \mathrm{~cm}$ 以下 の小照射野が用いられている。この小照射野領域ではビ 一ム幅が狭いために側方の 2 次電子平衡が成り立たず, 従来用いられている電離箱による線量評価が困難であり, 個々の施設において独自に行われているのが現状である.

フィルム法による線量評価は黒化度を吸収線量に変換
する特性曲線が必要になる，しかしフィルムに一定の黒 化度を与えるモニター指示值 (monitor unit：以下 MU) を用いることにより相対的評価が可能になる.

放射線治療における高エネルギーX線および電子線の 吸収線量の標準測定法 ${ }^{1)}$ による照射野係数 $\mathrm{F}_{\mathrm{A}}(\mathrm{A})$ の定 義は(1)式により与えられる。

$$
F_{A}(A)=D_{r}(A) / D_{r}(A=10 \times 10)
$$

$\mathrm{D}_{\mathrm{r}}(\mathrm{A})$ は照射野 $\mathrm{A}$ における基準点吸収線量である。照射 野 $\mathrm{A}$ において一定の基準点吸収線量を与えるために必要 なモニター線量単位を $\mathrm{MU}\left(\mathrm{A}_{\mathrm{x}}\right)$ とすると次の(2)，(3)式 が成り立つ。 


$$
\begin{aligned}
& D_{\mathrm{r}}(\mathrm{A})=\mathrm{MU}\left(\mathrm{A}_{\mathrm{X}}\right) \cdot \mathrm{F}_{\mathrm{A}}(\mathrm{A}) \\
& \mathrm{D}_{\mathrm{r}}(\mathrm{A}=10 \times 10)=\operatorname{MU}\left(\mathrm{A}_{10}\right)
\end{aligned}
$$

ここで, $\mathrm{D}_{\mathrm{r}}(\mathrm{A}=10 \times 10)=\mathrm{D}_{\mathrm{r}}(\mathrm{A})$ とすると

$$
\mathrm{F}_{\mathrm{A}}(\mathrm{A})=\mathrm{MU}\left(\mathrm{A}_{10}\right) / \mathrm{MU}\left(\mathrm{A}_{\mathrm{x}}\right)
$$

即ち，モニタ一線量単位 $\mathrm{MU}\left(\mathrm{A}_{10}\right)$ により照射野 $10 \times 10$ $\mathrm{cm}$ の基準深の吸収線量と同一吸収線量を照射野 $\mathrm{A} の$ 基 準深に与えるモニタ一線量単位を $\mathrm{MU}\left(\mathrm{A}_{\mathrm{X}}\right)$ とすると照 射野 $\mathrm{A}$ の照射野係数 $\mathrm{F}_{\mathrm{A}}$ は両者の比として(4)式で表され る。

我々は高エネルギーX線の小照射野領域における $F_{\mathrm{A}}$ の測定について，基準深で一定のフィルム黒化度を与え るための MU を求めることで $\mathrm{F}_{\mathrm{A}}$ を算出する方法につい て検討を行った。

\section{2. 方 法}

今回使用した装置および各検出器の規格, 仕様は次の とおりである。

1) 医用直線加速器: MEVATRON 77DX67

2）線量計：応用技研製

(1)電位計 $\mathrm{AE}-132 \mathrm{a}$

(2)電離箱 $\mathrm{c}-110: 0.6 \mathrm{ml}$

内径 $6 \mathrm{~mm}$, 長さ $22.3 \mathrm{~mm}$, 壁厚 $0.059 \mathrm{~g} / \mathrm{cm}^{2}$

3）ダイレクト線量計：スキャンジトロニクス社製 DPD-510

4）ダイオード検出器：スキャンジトロニクス社製 EDD-5：p-Si ダイオード

内径 $1.5 \mathrm{~mm}$, 長さ $0.5 \mathrm{~mm}$, 壁厚 $0.405 \mathrm{~g} / \mathrm{cm}^{2}$

5) フィルム：コニカ CS100E (リスコンタクト)

6）濃度計：マイクロデンシトメータ. Konica PDM- 5

7) ファントム $\mathrm{MixDP}(40 \mathrm{~cm} \times 30 \mathrm{~cm})$

8）自動現像機：フジ FPM-1300

\section{1 再現性について}

同一MUで照射したときのフィルム黒化度のバラツ

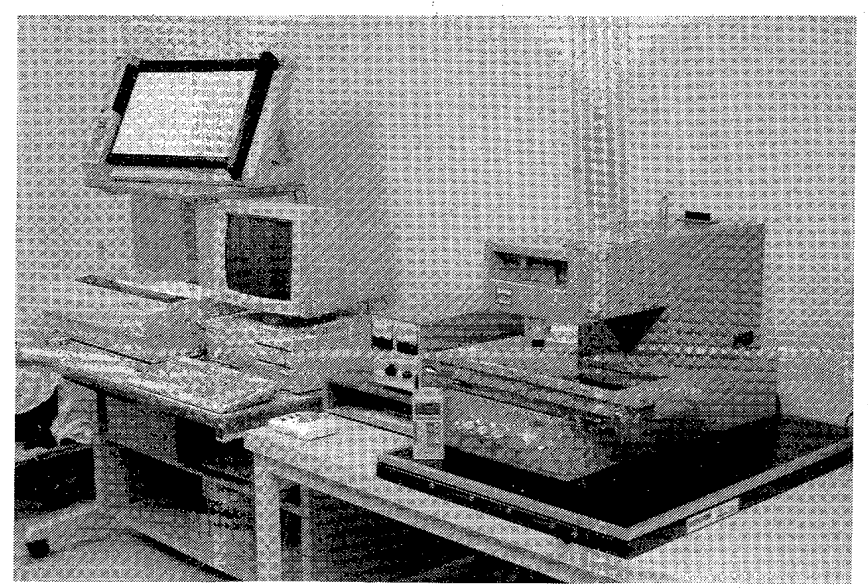

Fig. 1 Microdensitmeter (Konica PDM-5).
キを調べるために以下の測定を行った。

$\operatorname{MixDp}$ ファントム中深さ $3 \mathrm{~cm}$ (当施設のピーク深)に おいてビーム軸に垂直になるようにフィルムを扦入し， 線源・フィルム間距離（SFD）を $100 \mathrm{~cm}$ とし照射野3.6 $\mathrm{cm} \phi$ および $10 \times 10 \mathrm{~cm}$ において各々 10 枚のフィルムに 10MV X線（実効エネルギー：11.0 MV）を用いて照射 を行った。次にモニタ一線量計の信頼性を確認するため に同一MUにて繰り返し照射を行った，照射野 $10 \times 10$ $\mathrm{cm}$ 深さ $3 \mathrm{~cm}$ における吸収線量をリファレンス線量計 にて測定した。チャンバーは JARP 形を使用した。

\section{2 線量比の測定}

各照射野に扔いて照射したフィルムの同一黒化度を与 えるMUを求める方法は以下の測定を行った。

MixDp ファントム中深さ $3 \mathrm{~cm}$ にビーム軸に垂直に なるようフイルムを挿入し, $\mathrm{SFD}$ 照射野 $10 \times 10 \sim 4 \times 4 \mathrm{~cm} ，$ お よび円形照射野 $3.6 \sim 0.9$

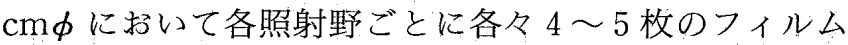
に10 MV-X線にて照射を行った. MU 注今回1.3前後の 黒化度が得られるように設定した。なおフィルム測定は すべて裸で行った。黑化度測定はマイクロデンシトメー ターを用い，100×100 $\mu \mathrm{m}$ のスリットサイズでスキャン を行った。正方形照射野 $4 \times 4 \sim 10 \times 10 \mathrm{~cm}$ では照射野中 心から左右 $3 \mathrm{~mm}$ 間を測定点にとり，その平均黒化度を

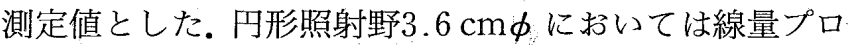

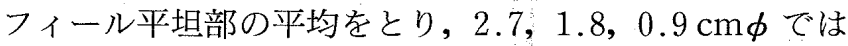
ピークを測定值とした。黑化度と MU の相関を求めるた めに最小二乗法により近似式を求め各照射野ごとの黒化 度-MU 曲線を作成した。この曲線加ら黒化度1.3におけ る $\mathrm{MU}$ を求め, 前述の(4)式から線量比を算出した。線量 比測定の信頼性を確認するため, 電離箱およびダイオー ドを用いて同様の設定条件で測定を行った。

\section{3. 結果}

\section{1 再現性について}

Table 1 に同一MUにて10回照射されたフィルムの 黒化度の平均値と標準偏差 ${ }^{2}$ を示す，正方形照射野 $10 \times$ $10 \mathrm{~cm}$ および円形照射野 $3.6 \mathrm{~cm} \phi$ にお ける標準偏差は $0.017 ， 0.015$ であった。両者の変動係数は共に $1 \%$ であ

Table 1 Standard deviation (SD) of film densities irradiated at the same MU.

\begin{tabular}{l|c|c}
\multirow{2}{*}{$\begin{array}{l}\text { Field } \\
\text { size }(\mathrm{cm})\end{array}$} & $\begin{array}{c}\mid c \\
\text { Mean } \\
(\mathrm{n}=10)\end{array}$ & $\begin{array}{c}\mathrm{SD}^{*} \\
(\mathrm{n}=10)\end{array}$ \\
\hline $10 \times 10$ & 1.566 & 0.017 \\
$3.6 \phi$ & 1.496 & 0.015
\end{tabular}

* SD : Standard deviation 
りバラツキは極めて少なかった。

次に同一MUにて照射された吸収線量の10回の指示 值の平均值は $\mathrm{MU}$ が30,60,180では31.61, 63.03, 188.95 cGyであり，各々の標準偏差は0.032，0.048，0.053であ った.MUが30，60および180の場合の変動係数は共に $0.1 \%$ 以内であった。

またりファレンス線量計の測定の平均值と MU 值の 比はMUが30,60,180において1.054, 1.051, 1.050 cGy/ MUであった。モニター線量計の直線性は良好であった

Table 2 Correlation between monitor unit (MU) and absorbed doses.

\begin{tabular}{|c|c|c|c|}
\hline \multirow[b]{2}{*}{ mu } & \multicolumn{2}{|c|}{$A D^{*}$} & \multirow[b]{2}{*}{$A D / M U^{\neq * *}$} \\
\hline & $\begin{array}{l}\text { Mean } \\
(n=10)\end{array}$ & $\begin{array}{c}S D^{* *} \\
(n=10)\end{array}$ & \\
\hline 30 & 31.61 & 0.032 & 1.054 \\
\hline 60 & 63.03 & 0.048 & 1.051 \\
\hline 180 & 188.95 & 0.053 & 1. 050 \\
\hline
\end{tabular}

* ND: Absorbed Dose measured by reference dosimete

\# SO : Standard Deviation.

\#\#\# : Monitor Unit.

Table 3 MU and density according to field size.

\begin{tabular}{ccc}
$\begin{array}{l}\text { Field } \\
\text { size }(\mathrm{cm})\end{array}$ & MU & Density \\
\hline $10 \times 10$ & 50 & 1.631 \\
& 45 & 1.296 \\
& 40 & 1.267 \\
& 35 & 1.163 \\
& 30 & 0.973 \\
\hline $8 \times 8$ & 46 & 1.404 \\
& 41 & 1.319 \\
& 36 & 1.145 \\
& 31 & 0.989 \\
\hline $6 \times 6$ & 47 & 1.408 \\
& 42 & 1.292 \\
& 37 & 1.148 \\
& 31 & 0.989 \\
\hline $4 \times 4$ & 49 & 1.430 \\
& 44 & 1.314 \\
& 38 & 1.091 \\
& 33 & 0.991
\end{tabular}

\begin{tabular}{ccc}
$\begin{array}{l}\text { Field } \\
\text { size(can) }\end{array}$ & $M U$ & Density \\
\hline $3.6 \phi$ & 49 & 1.344 \\
& 44 & 1.203 \\
& 38 & 1.077 \\
33 & 0.880 \\
\hline $2.7 \phi$ & 50 & 1.339 \\
& 44 & 1.198 \\
& 39 & 1.067 \\
\hline $1.8 \phi$ & 33 & 0.880 \\
\hline & 47 & 1.352 \\
& 41 & 1.193 \\
$0.9 \phi$ & 35 & 0.913 \\
\hline & 65 & 1.307 \\
& 57 & 1.146 \\
& 50 & 1.128 \\
& 43 & 0.840
\end{tabular}

Table 4 Output factor measured by film dosimetry, ionization chamber and semiconducor detector.

\begin{tabular}{l|c|c|c}
\multirow{2}{*}{$\begin{array}{l}\text { Field } \\
\text { size }(\mathrm{cm})\end{array}$} & \multicolumn{3}{|c}{ Output factor } \\
\cline { 2 - 4 } $10 \times 10$ & 1.000 & $\begin{array}{l}\text { lonization } \\
\text { chamber }\end{array}$ & $\begin{array}{c}\text { Semiconductor } \\
\text { detector }\end{array}$ \\
\hline $8 \times 8$ & 0.978 & 0.981 & 1.000 \\
$6 \times 6$ & 0.950 & 0.955 & 0.977 \\
$4 \times 4$ & 0.918 & 0.915 & 0.949 \\
$3.6 \phi$ & 0.929 & & 0.915 \\
$2.7 \phi$ & 0.904 & & 0.917 \\
$1.8 \phi$ & 0.856 & & 0.900 \\
$0.9 \phi$ & 0.696 & & 0.851
\end{tabular}

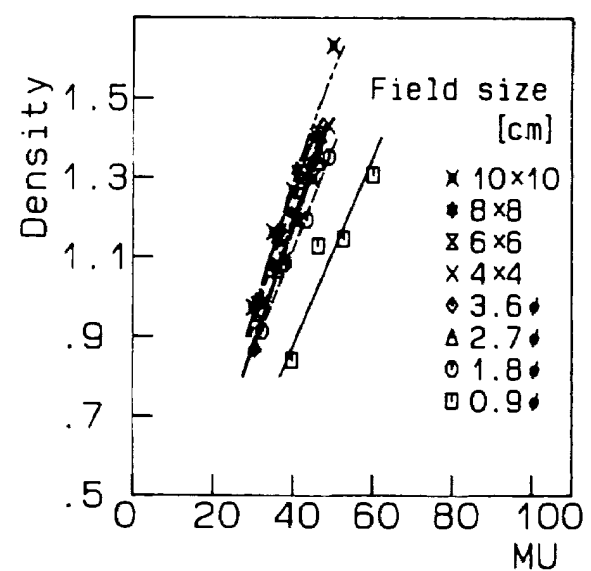

Fig. 2 Density-MU curves.

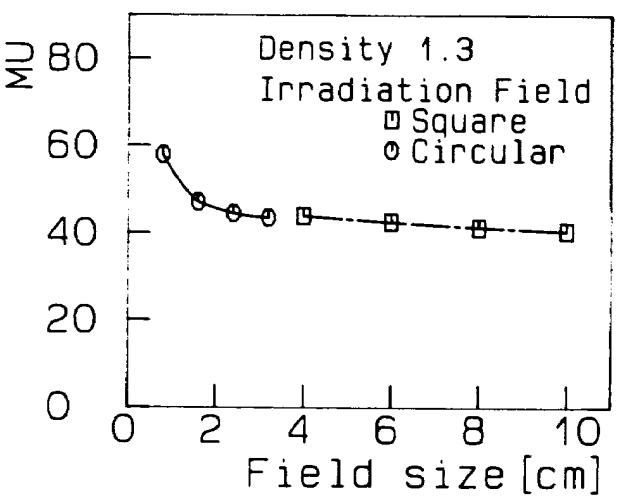

Fig. 3 MU-field size curve.

(Table 2)．フィルム黒化度およびMUにおける繰り返 し測定についての再現性は極めて良好であった。

\section{2 線量比の測定}

(1) Table 3 に測定した黒化度，MUの值を示す。

(2) Fig. 2 の各直線は最小二乗法で求めた直線を示す. (3)計算した直線から各照射野における同一黒化度を得 るに必要な MU 值を算出した。

黒化度1.3に扔ける各照射野とMUとの計算結果を Fig. 3 に示す.

フィルム黒化度と MU から算出した線量比と電離箱 およびダイオード検出器による測定值の比較を Table 4 に示す．正方形照射野 $10 \times 10 \mathrm{~cm} \sim 4 \times 4 \mathrm{~cm}$ においては フィルムと MUから求められる線量比と電離箱および ダイオード検出器により測定された線量比の值は極めて 良く一致した。また $3.6 \mathrm{~cm} \phi$ 以下の円形照射野において もフィルムとMUから求められる線量比とダイオード 検出器により湘定された線量比の值は極めて良く一致し た。

\section{4. 考察}

装置のモニター線量計は加速器へッド内に取り付けら れていることから照射野の大きさに依存すること無く一 
定にX線が照射される. 照射野が小さくなり2次コリメ ータによる後方散乱で MUが増加したとしても増加さ れたMUとリファレンス線量計による测定值から照射 野係数は算出される。

フィルム法による線量測定の誤差は正規分布に従うと 考えられる．すなわち測定の回数を増やすことにより， より正確な值が得られることを意味する。しかし実験装 置ではない医用直線加速器を利用した測定において測定 数を増やすことは装置の寿命や日常の業務に影響を及ほ すなどの問題もある。フィルムによる測定の使用範用は 電離箱で測定不能なナロー・ビーム領域に限定されるが， 電離箱を基準とした相対測定とすることで誤差を小さく できる。

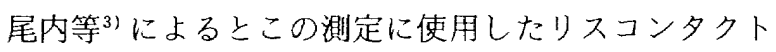
フィルムのエネルギー依存性は小さいとしている。また， 測定梁を一定としていることで梁部における散乱線寄与 による誤差は少ないと考えられる。

フィルム法の誤差の原因については現像処理中に多い という報告がある4). 現像時の $0.1^{\circ}$ の温度差が黒化度に $1 \%$ 䛊差を与えるとしている.しかし現在の自動現像 機は小数点一桁まで温度表示がされており, 一定の温度 でフィルム操作が行える。また特性曲線からの線量変換 を行わないため一日で実験を終了させることで現像日時 の違いによる変化は避けられる。この様に黑化度に影響 を及ぼす因子を除けば，フィルム法の誤差は低く抑えら れる。

今回のフィルムによる線量比測定は黒化度のバラツキ
を十分考慮にいれれば簡素化された方法であり, 実務上 簡便な測定方法として使用可能であると考える.

\section{5. 結語}

1.同一MUにて照射されたフィルムの黒化度の変動 係数は約 $1 \%$ であった。

2.フィルムを使用した MUによる線量比の測定值は 電離箱およびダイオードの測定值と極めて良く一致した。

3.フィルムを使用したMUによる線量比測定方法は フィルム黒化度を吸収線量に変換することなく線量比の 算出が可能である。

4.フィルムを使用した MUによる線量比の测定は, 電離箱ちよびダイオード等で測定不能な極小照射野の測 定に使用可能である.

\section{参考文献}

1）日本医学放射線学会物理部会編：放射線治療におけ る高エネルギーX線抢よび電子線の吸収線量の標準 测定法, 通商産業研究社, 東京, (1989).

2）市原清志：バイオサイエンスの統計学, 南江堂, 東 京, (1991).

3）尾内能夫, 都丸禎三, 入船寅二, 他: 写真フィルム による高エネルギーX線の線量分布湘定法の再検討, 日医放会誌, 31，1224-1236 (1972).

4) ICRU Report 35: Radiation dosimetry, Electron beams with energies between 1 and $50 \mathrm{MeV}, 92-$ 95, ICRU Bethesda Maryland, (1984). 